Article

\title{
Regional Economic Resilience in the Central-Cities and Outer-Suburbs of Northeast China
}

\author{
Qiao Li ${ }^{1}$, Haoming Guan ${ }^{2,3, *,+}$, Zhangxian Feng ${ }^{2,3, *, \dagger}$ and Wang Long ${ }^{2}$ \\ 1 School of Architecture, Changchun Institute of Technology, Changchun 130021, China; liq869@nenu.edu.cn \\ 2 School of Geographical Sciences, Northeast Normal University, Changchun 130024, China; \\ longw477@nenu.edu.cn \\ 3 Key Laboratory of Geographical Processes and Ecological Security in Changbai Mountains, \\ Ministry of Education, Northeast Normal University, Changchun 130024, China \\ * Correspondence: guanhm410@nenu.edu.cn (H.G.); fengzx092@nenu.edu.cn (Z.F.) \\ + These authors contributed equally to this work.
}

Citation: Li, Q.; Guan, H.; Feng, Z.; Long, W. Regional Economic

Resilience in the Central-Cities and Outer-Suburbs of Northeast China. Sustainability 2022, 14, 2844.

https://doi.org/10.3390/su14052844

Academic Editor: Marc A. Rosen

Received: 30 December 2021

Accepted: 23 February 2022

Published: 28 February 2022

Publisher's Note: MDPI stays neutral with regard to jurisdictional claims in published maps and institutional affiliations.

Copyright: () 2022 by the authors Licensee MDPI, Basel, Switzerland. This article is an open access article distributed under the terms and conditions of the Creative Commons Attribution (CC BY) license (https:// creativecommons.org/licenses/by/ $4.0 /)$.

\begin{abstract}
The global economic downturn and the new normal status of China's economy have revealed that the Northeastern region of the country is facing challenges due to poor adaptability and weak regional economic resilience. In regard to the regional cities of China's municipal-administered county system and from the perspective of the relationship between the economic resilience of the central-cities and the outer-suburbs, it is helpful to explore the characteristics of the regional economic resilience in Northeast China from 2007 to 2018. We find that: (1) The economic resilience of the centralcities and outer-suburbs in Northeast China has deteriorated. Compared with the central-cities, the economic resilience of outer-suburbs has weakened even more. (2) The types of regional economic resilience of the central-cities and outer-suburbs of Northeast China have diversified and weakened. The main types of economic resilience have changed from city-prospered-suburb-prospered and city-balanced-suburb-prospered to city-balanced-suburb-balanced and city-declined-suburb-declined. There are differences in the types of municipal economic resilience that are affected by changes in the economic resilience levels of central-cities and outer-suburbs. (3) It is further confirmed that the industrial structure has an important influence on the resilience of the regional economy. The economic resilience of the outer-suburbs in the Northeast China appear to be more vulnerable and more heavily influenced by changes in the proportion of the secondary industry than the central-cities.
\end{abstract}

Keywords: regional economic resilience; central-cities; outer-suburbs; combination patterns; Northeast China

\section{Introduction}

Because of economic globalization and other global changes, contemporary economic development is facing an increasing number of shocks and disturbances. Maintaining stable economic development has become one of the most important issues that needs to be resolved urgently in various countries and regions [1-3]. China can be divided into four regions - eastern, central, western and northeast-based on economics, history and geography. The eastern coastal areas are relatively developed in comparison to the other regions. In conjunction with a decline in the national economic growth rate since 2012, the economy in Northeast China has declined drastically. In fact, some cities have even experienced negative growth. These areas have experienced difficulties with development and have once again become "problem areas" in the "Rust Belt" of China, which has attracted much attention [4,5]. In 2020, there were about 23 cities throughout China that were joining the " 1 Trillion Yuan GDP Club"; however, none of these cities are located in the Northeast. Similarly, the number of counties in the "100 Billion Yuan GDP Club" increased to 33 in the same year, but again there were no counties from the Northeast region represented. In 2020, there was another list of the "Top 100 Counties" in China. 
This list contained only three counties from Liaoning Province in Northeast China, as both Jilin Province and Heilongjiang Province were absent from the list. Since 2014, the State Council has issued a series of revitalization and support policies aimed at preventing a continued economic slowdown in Northeast China and improving the quality and efficiency of economic development. However, with the pressure of an external economic downturn, long-term institutional and structural problems, and social and economic vulnerability, it is difficult to accomplish comprehensive revitalization [4]. Although there have been many studies in the relevant literature regarding regional economic resilience, there have been few that have focused on Northeast China [6,7].

Since the international financial crisis in 2008, the study of regional economic resilience has gradually become a hot topic in economic geography at home and abroad. Scholars have attributed the issue of how a region responds to shocks and disturbances in an effort to maintain the stable development of the regional economy as regional economic resilience, and a series of studies on the concept, theoretical framework, measurement and influencing factors have been conducted [8-12]. Existing studies have generally taken the whole country, regions, provinces or cities as the basic units, focusing on the differences in regional economic resilience, while little research has paid attention to the differences in economic resilience in a central city compared with rural or suburb area [13-15]. China maintains a system of county under the jurisdiction of administrative city, and the city administrative area is a combination of the central city and peripheral counties [16]. The central city and peripheral counties have important functions in terms of the economy, industry and urbanization. In light of the new economic normal in China, what is the difference in the economic growth stability of the central-cities and the outer-suburbs, and what type of relationship does it have? It is important to understand how to maintain the stability of the economic development of regional cities in China, but research that focuses on the special unit of locality is needed.

Based on the concept of regional economic resilience, our study explores the characteristics of the economic resilience of cities in Northeast China from the perspective of the relationship between the central-cities and the outer-suburbs. Thus, this paper focuses on two aspects: (1) the differences in the level of economic resilience between the central-cities and outer-suburbs in Northeast China and (2) the change and spatial distribution of the regional economic resilience type characterized by the combination model of the economic resilience level of the central-cities and the outer-suburbs. We offer a preliminary exploration of the impact of industrial structure on the economic resilience of central-cities and outer-suburbs.

\section{Literature Review}

Regional economic resilience has been studied in terms of why some regions can resist and resolve the crises and adaptively embark on the road of development, while others cannot adapt to changes and may even go into a recession $[17,18]$. So far, there are three views on regional economic resilience. The first emphasizes the adaptation process of the region in regard to capacity and resilience in the face of a sudden short-term disturbance $[19,20]$. The other two views emphasize the ability of the region to seek a new growth path (a new industry) to rebuild social and economic structure under a gradual longterm persistent disturbance [21], and they emphasize the process and dynamic mechanism of regional economic evolution in a specific context [22]. Overall, since the 2008 global financial crisis, the definition and connotation of regional economic resilience have been continuously refined. Martin defined regional economic resilience as the resistance of a region to its development path affected by impacts such as the market, competition and environment [23].It includes the ability to recover from shocks to the original development path, which is regarded as recovery or adjusting its own structure to adapt to the new external environment as a structural reorientation. And it involves the ability to create a new development path as a renewal of the growth path, among which resistance and recovery are two key processes in the change of regional economic resilience [24]. This 
definition comprehensively summarizes the connotation of regional economic resilience from four dimensions and is the most commonly used in empirical research.

The measurement of economic resilience and the analysis of influencing factors are the two most important issues for empirical research. In terms of existing measurement studies, it is based on the core variable method proposed by Martin [25], which considers the 2008 financial crisis or the cyclical rise and fall of one national economy as shock disturbances. It also adopts simple macroeconomic indicators-such as GDP-to construct a sensitivity index to measure the recovery and resistance of regional economic resilience. Under this paradigm, scholars have carried out many studies using data from Europe, Italy, Canada and China-including provinces in China, the Yangtze River Delta, the Pearl River Delta and the cities of Northeast China -to measure and compare the differences in economic resilience in different regions [26-34]. Much attention has been paid to differences in economic resilience among countries, regions and cities, but there has been a lack of research on differences between urban and rural areas.

The influencing factors of regional economic resilience include industrial structure, knowledge networks, the institutional environment, technological innovation, human capital, industry types, etc. $[21,35,36]$, and researchers have found that industrial structure has been the most vital factor affecting regional economic resilience. Factors such as the diversity of the industrial structure and the types of leading industries have been studied because different industries have different sensitivities to shock disturbances [37]. Widely speaking, regions with a higher proportion of the secondary industry dominated by traditional manufacturing tend to have poor economic resilience. In terms of the diversity of industrial structure, regions with a higher degree of specialization tend to have higher production capacity and efficiency, and diversified regions are more capable of responding to shocks and disturbances than specialized regions [38]. Overall, the literature maintains that industry structure plays a vital role in regional economic resilience, but there have been few studies that have focused on the industry structure effect on the differences between urban and rural economic resilience.

With this in mind, we constructed our research to examine the characteristics of regional economic resilience from the perspective of center and peripheral counties. We used the core variable method of measurement, the selection of GDP indicators and the decline in China's economic growth from 2007 to 2018 as shock disturbances. We constructed a sensitivity index to measure the economic resilience of the central-cities and outer-suburbs, respectively; defined the combination model of the economic resilience of the central-cities and outer-suburbs in the city administrative area according to the level of economic resilience and the combination result; classified the city administrative area types; and explored the impact of industrial structure on the economic resilience of central-cities and outer-suburbs.

\section{Study Area and Dataset}

\subsection{Study Area}

With a total area of 1,244,200 $\mathrm{km}^{2}$, Northeast China includes Heilongjiang Province, Jilin Province, Liaoning Province and four cities in Eastern Inner Mongolia (Hulunbuir, Tongliao, Chifeng, Xing'an League). We built on the work of several sources $[16,39,40]$ to define the district under the jurisdiction of the city as the central-cities. The counties, banners and county-level cities under the jurisdiction of the city were defined as the outersuburbs. However, for 2018, we excluded the Greater Xing'an Mountains and the Xing'an League and Yanbian prefectures that were not divided into districts. Instead, we selected 37 city administrative areas at the prefecture-level and above, for a total of 151 districts and 160 counties (banners and county-level cities) under its jurisdiction. For instance, for GDP in 2018, the economic scale ratio of the central-cities and outer-suburbs in the Northeast region was $1.58: 1$, accounting for $6.80 \%$ and $6.78 \%$ of the corresponding units in the country, respectively. 


\subsection{Period and Dataset}

Figure 1 shows the national GDP growth rate and the changes in the three industrial structures from 1978 to 2018. Among them, the economic growth rate fluctuated considerably in the first 20 years, and it changed periodically in the next 20 years. Since 2007, as a result of the global financial crisis, China's economic growth has gradually declined. And from 2012, the high-speed growth of 10\% per year-which had been occurring for nearly 30 years - ended and then turned into medium-to-high-speed growth. The industrial structure has also undergone major changes. The overall trend has been from "secondary, primary, tertiary" to "secondary, tertiary, primary" and then to "tertiary, secondary, primary." In 2012, the tertiary industry accounted for more than the secondary industry's share of GDP. Based on the above characteristics and referring to related research [5], we used the "peak-to-peak" method (measuring from one peak to another for one economic cycle) to divide the national economic cycle into expansion and contraction [41]. The results showed expansion for the periods of 1978-1981, 1984-1990, 1984-1990, 1992-1999, 2007-2011 and 2011-2018, while the periods of 1981-1984, 1990-1992 and 1999-2007 showed contraction. Our research focused on 2007-2018 when economic growth was contracting, including contractions in 2007-2011 and 2011-2018. The data used came from the 2008-2019 China City Statistical Yearbook.

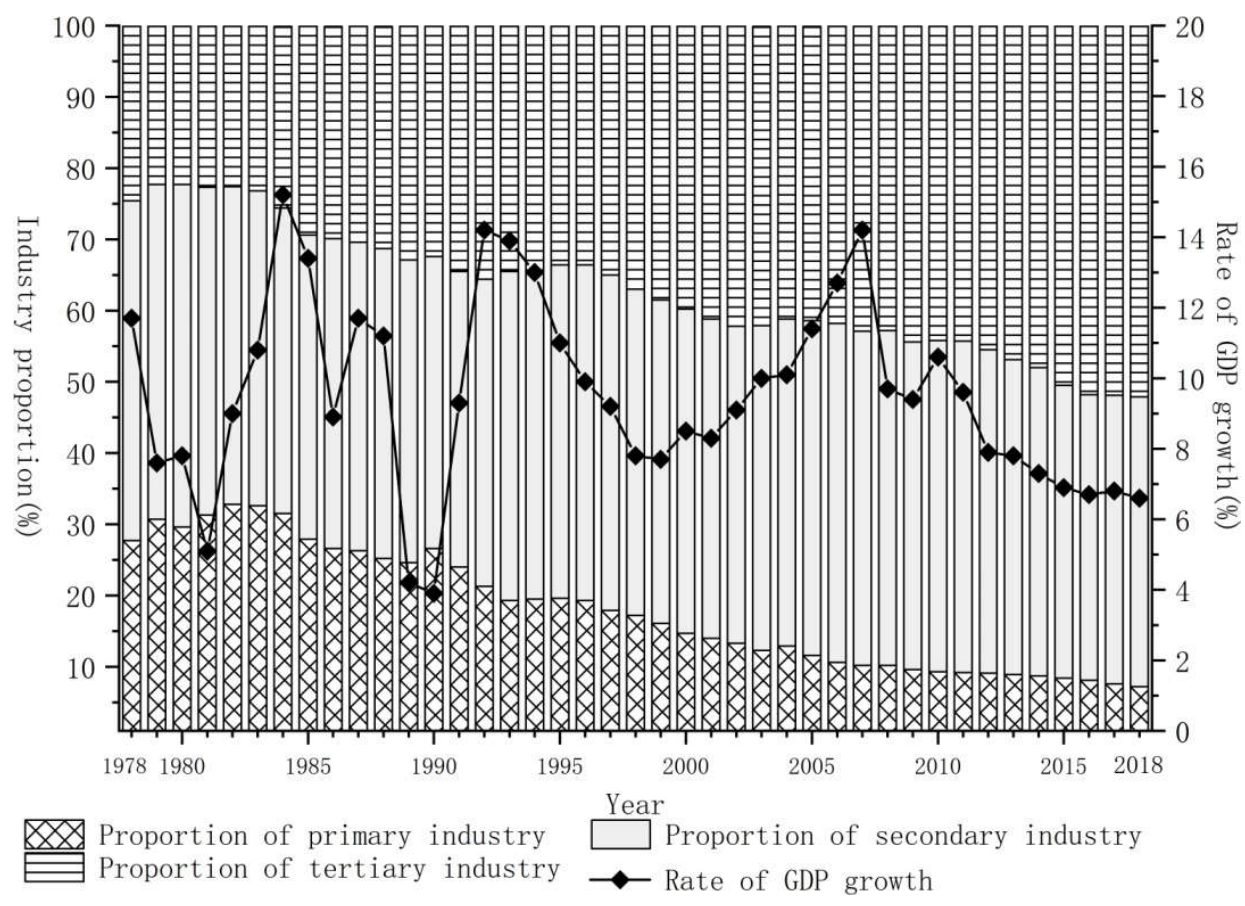

Figure 1. The changes in China's economic growth and industrial structure from 1978 to 2018.

\section{Methods}

We used Martin's [19] measurement method to examine the relative resilience level of each research object in response to a shock disturbance (Equation (1)):

$$
\begin{gathered}
\left(\Delta G_{n}^{t+k}\right)^{\text {expected }}=g_{N}^{t+k} G_{n}^{t} \\
\operatorname{Resis}_{n}=\frac{\left(\Delta G_{n}^{\text {Contraction }}\right)^{\text {Actual }}-\left(\Delta G_{n}^{\text {Contraction }}\right)^{\text {expected }}}{\left|\left(\Delta G_{n}^{\text {Contraction }}\right)^{\text {expected }}\right|}
\end{gathered}
$$

In Equation (1), $g_{N}^{t+k}$ represented the growth rate of national GDP during the contraction period, and $G_{n}^{t}$ represented the GDP scale of a certain research object at the initial stage t. Resis $n$ was a positive value of Resis ${ }_{n}$, indicating that the resistance of an object were better 
than the national average-that is, stronger resilience-while a negative value indicated weaker resilience. To avoid the impact of administrative divisions and the unequal number of central-cities and outer-suburbs in each city area, we selected the average GDP of the central-cities and outer-suburbs, which was the total GDP of the year divided by the central-cities or the number of administrative district units in outer-suburbs.

Although the Chinese economy has maintained positive growth since 2007, some regions have actually experienced negative economic growth. Thus, the "dichotomy" of positive and negative resilience values neglects to distinguish between the absolute decline and the relative decline of the economic growth of each research object. Therefore, we introduced the "rule of thirds" to improve the above-mentioned toughness value. According to Equation (2), if Resis $n \geq 0$, it indicated strong resilience; if Resis ${ }_{n}$ were between 0 and -1 , it indicated relatively moderate resilience, meaning that if the economic growth rate of a certain object were slower than the national average, it still maintained positive growth; Resis $_{n} \leq-1$ indicated weak resilience, meaning that the economic growth rate of a certain object were 0 or negative.

On the basis of the above method, in consonance with the combination pattern of the economic resilience level of the central-cities and the outer-suburbs, the city administrative area was divided into nine types (Table 1). We used two methods to more clearly characterize the types of city administrative areas. Using the first method, we divided the level of resilience into "strong, medium and weak," which corresponded to the "prosperity, balance and decline" of economic growth. Using the second method, we abbreviated the central urban area as a city and the outer-suburbs as a suburb. Therefore, the nine types of cities were: I city-prospered-suburb-prospered, II city-prospered-suburb-balanced, III city-prospered-suburb-declined, IV city-balanced-suburb-prospered, V city-balancedsuburb-balanced, VI city-balanced-suburb-declined, VII city-declined-suburb-prospered, VIII city-declined-suburb-balanced and IX city-declined-suburb-declined. Among them, types I, II, IV and V are regarded as the ideal conditions, while types III, VI, VII, VIII and IX are the least desirable conditions.

Table 1. Types of city administrative areas.

\begin{tabular}{lc}
\hline \multicolumn{1}{c}{ Types } & Symbol \\
\hline City-prospered-suburb-prospered & $\mathrm{I}$ \\
City-prospered-suburb-balanced & $\mathrm{II}$ \\
City-prospered-suburb-declined & $\mathrm{III}$ \\
City-balanced-suburb-prospered & $\mathrm{IV}$ \\
City-balanced-suburb-balanced & $\mathrm{V}$ \\
City-balanced-suburb-declined & $\mathrm{VI}$ \\
City-declined-suburb-prospered & $\mathrm{VII}$ \\
City-declined-suburb-balanced & $\mathrm{VIII}$ \\
City-declined-suburb-declined & $\mathrm{IX}$ \\
\hline
\end{tabular}

\section{Results}

\subsection{Characteristics of Central-Cities and Outer-Suburbs Economic Resilience}

According to the economic resilience value, the level of economic resilience in the central-cities and outer-suburbs in Northeast China changed significantly from 2007 to 2018 (Figure 2). From 2007 to 2011, the economic resilience values of the central-cities and outersuburbs were relatively moderate, with average values of 0.037 and 0.524 , respectively. The average economic resilience level was relatively strong, and the outer-suburbs were stronger than the central-cities. From 2011 to 2018, the average economic resilience of the centralcities and outer-suburbs were -0.951 and -0.854 , respectively. Although the average economic resilience was at a relatively moderate level, it was close to the weak resilience level. About $40 \%$ of the central-cities and outer-suburbs had weak economic resilience. 


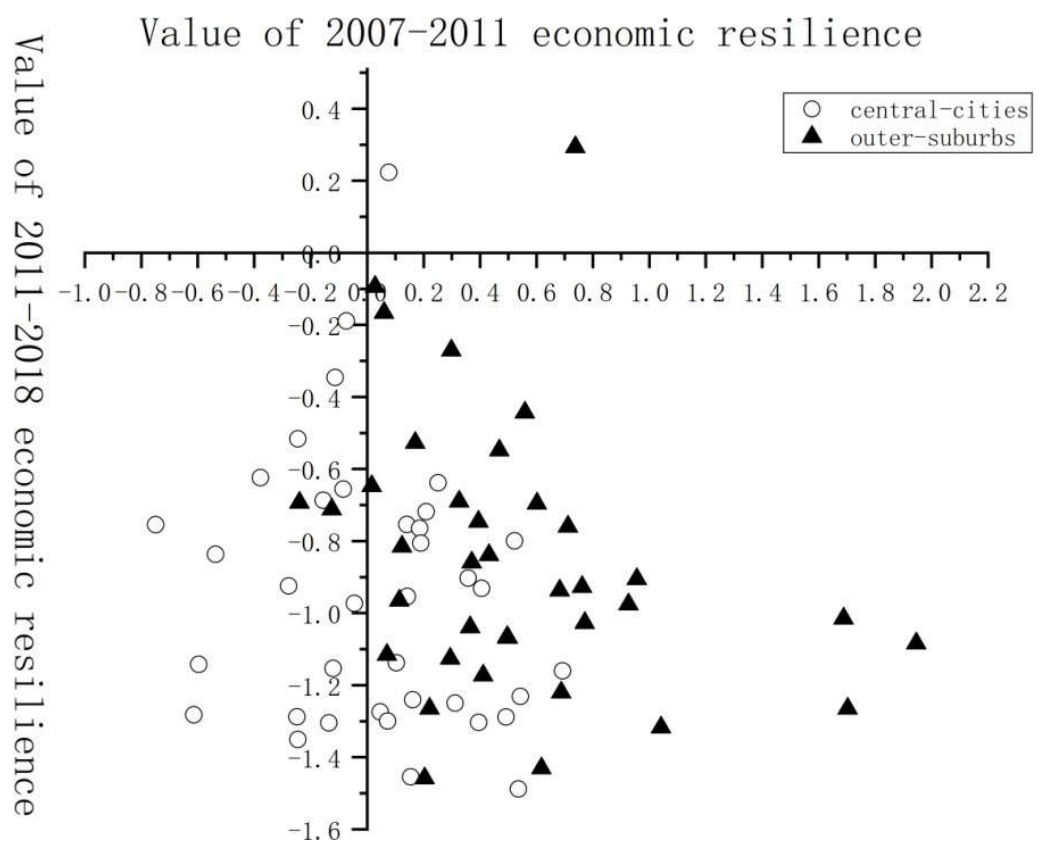

Figure 2. The level of economic resilience of the central-cities and outer-suburbs in Northeast China from 2007 to 2018.

From the perspective of the two-stage changes, the economic resilience average of the central-cities and outer-suburbs decreased by 0.988 and 1.378 , respectively, and about $70 \%$ of the central-cities had declining economic resilience levels. At the same time, 11 central-cities had weakening economic resilience, accounting for nearly $30 \%$. Approximately $92 \%$ of the outer-suburbs had a reduced level of economic resilience; among them, 16 samples—roughly $40 \%$ - had turned from strong resilience to weak resilience. By analyzing the correlation between the economic resilience of the central-cities and the outersuburbs in the two respective stages, we discovered a negative correlation (the correlation coefficients were 0.174 and 0.292 , respectively), which further illustrated the economic resilience of the outer-suburbs compared to the central-cities.

\subsection{Temporal and Spatial Characteristics of Central-Cities and Outer-Suburbs Economic Resilience} Combination Pattern

In terms of the level of economic resilience, the results of the classification conforming to the nine combination patterns showed that the temporal and spatial changes of the economic resilience combination pattern of the central-cities and outer-suburbs in Northeast China were significant from 2007 to 2018 (Table 2 and Figure 3). In the period of 2007 to 2011, about $95 \%$ of the city administrative areas in Northeast China were classified as either city-prospered-suburb-prospered (54\%) or city-balanced-suburb-prospered (41\%). The city-prospered-suburb-prospered pattern was mainly distributed in the west and east of Northeast China, and the city-balance-suburb-prospered pattern was mainly in the middle and east of Northeast China. The main pattern in Liaoning Province was city-balanced-suburb-prospered. Heilongjiang Province was dominated by two types: city-prospered-suburb-prospered and city-balanced-suburb-prospered. The most common pattern in Jilin Province and Eastern Inner Mongolia was city-prospered-suburb-prospered. The four major central cities of Shenyang, Dalian, Harbin and Changchun all exhibited the city-balanced-suburb-prospered type. 
Table 2. The combination patterns of economic resilience of the central-cities and outer-suburbs in Northeast China from 2007 to 2018.

\begin{tabular}{|c|c|c|c|c|c|c|c|c|c|}
\hline Combination Patterns & I & II & III & IV & $\mathrm{V}$ & VI & VII & VIII & IX \\
\hline 2007-2011 & 20 & 1 & & 15 & 1 & & & & \\
\hline Liaoning Province & 5 & & & 9 & & & & & \\
\hline Jilin Province & 6 & & & 2 & & & & & \\
\hline Heilongjiang Province & 6 & 1 & & 4 & 1 & & & & \\
\hline Eastern Inner Mongolia & 3 & & & & & & & & \\
\hline $2011-2018$ & & 1 & & & 13 & 6 & 1 & 7 & 9 \\
\hline Liaoning Province & & & & & 3 & 5 & 1 & & 5 \\
\hline Jilin Province & & & & & 4 & 1 & & 3 & \\
\hline Heilongjiang Province & & 1 & & & 5 & & & 4 & 2 \\
\hline Eastern Inner Mongolia & & & & & 1 & & & & 2 \\
\hline
\end{tabular}

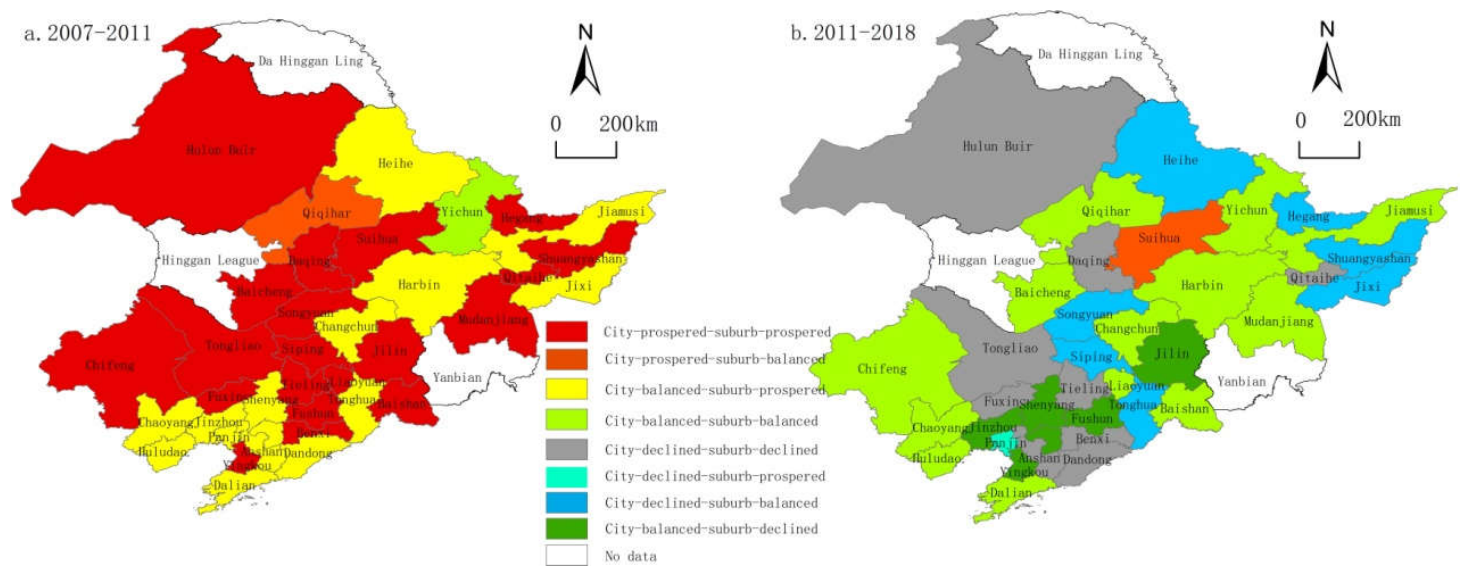

Figure 3. The spatial distribution of economic resilience combination modes of the central-cities and outer-suburbs in Northeast China from 2007 to 2018.

From 2011 to 2018, there were three types including city-balanced-suburb-declined, city-declined-suburb-balanced and city-declined-suburb-declined, which covered about $60 \%$ of the city administrative areas in Northeast China. Nearly $45 \%$ were distributed in Liaoning Province. The proportion of city-declined-suburb-declined type was nearly $41 \%$, with 56\% distributed throughout Liaoning Province; other city administrative areas were mainly the city-balanced-suburb-balanced type, which dominated in all provinces (autonomous regions). The main types in Liaoning Province were city-balanced-suburbdeclined and city-declined-suburb-declined, while the main types in Heilongjiang Province and Jilin were city-balanced-suburb-balanced and city-declined-suburb-balanced. The main type in Eastern Inner Mongolia was city-declined-suburb-declined, while the three major cities of Dalian, Harbin and Changchun exhibited the city-balanced-suburb-balanced type.

Comparing the changes in the above two stages, the types of city administrative areas in Northeast China have changed from four to six. Among them, the main types have changed from two types-city-prospered-suburb-prospered and city-balanced-suburbprospered-to city-balanced-suburb-balanced, city-declined-suburb-declined, city-declinedsuburb-balanced and city-balanced-suburb-declined. Among them, Suihua City maintained the city-prospered-suburb-balanced type, which presents a better condition. In addition, there emerged a city-declined-suburb-prospered type, which revealed the large contrast between the central and peripheral economic resilience, namely Panjin City in Liaoning Province. In terms of contrasting provinces, Liaoning Province and Eastern Inner Mongolia experienced enormous declines in terms of the distribution of types, with large losses in central-cities and the outer-suburbs. The distribution of types changed obviously and similarly in Heilongiiang Province and Jilin Province. The first two main patterns have converted from city-prospered-suburb-prospered and city-balanced-suburb-prospered to 
city-balanced-suburb-balanced and city-declined-suburb-balanced. Contemporaneously, the declines in central-cities were stark in comparison to the relatively limited declines in the outer-suburbs. These results suggested that the deterioration of the city administrative area types in Liaoning Province and Eastern Inner Mongolia was greatly affected by the lower economic resilience levels of the outer-suburbs and central-cities. Liaoning Province was especially affected by the outer-suburbs, while the city administrative area types of Heilongjiang Province and Jilin Province may have changed due to the lower economic resilience level of the central-cities.

\subsection{The Transition Characteristics of the Combination Patterns of Central-Cities and Outer-Suburbs Economic Resilience}

Figures 3 and 4 compare the transition of the economic resilience combination patterns in Northeast China, mainly the transition of two types-city-prospered-suburb-prospered and city-balanced-suburb-prospered-to other types. The two types represent about $54 \%$ and $41 \%$, respectively. From the perspective of changes in the scale of economic resilience of the central-cities and outer-suburbs, the transition from the city-prospered-suburbprospered to other types was concentrated in the consistency of the decline. At the same time, the gradient of the change into the city-balanced-suburb-balanced type accounted for about $25 \%$. The city-balanced-suburb-prospered type was chiefly presented in the inconsistency of the change range, while the prime change was the city-balanced-suburbbalanced type, with a proportion of about $40 \%$.

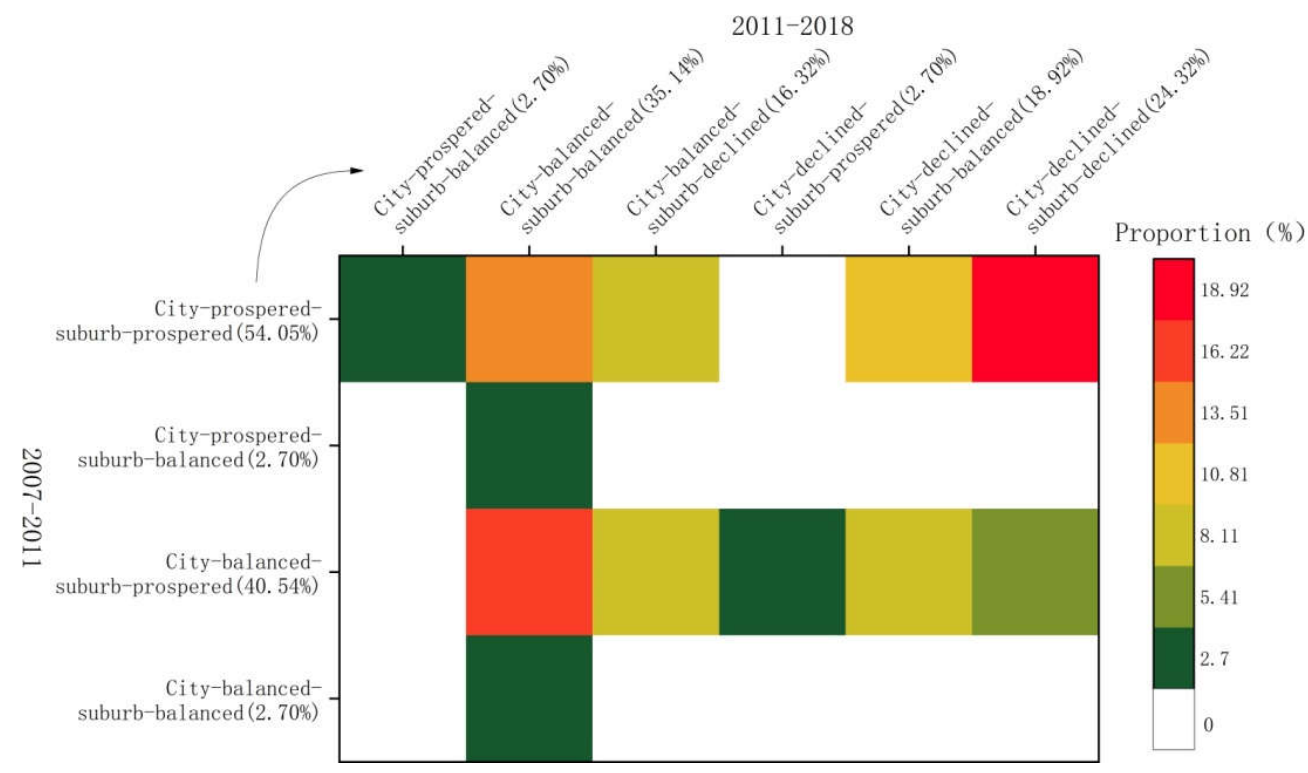

Figure 4. The transfer matrix of economic resilience combination modes of the central-cities and outer-suburbs in Northeast China from 2007 to 2018.

From the perspective of spatial distribution (Figures 3 and 4), the leap-forward transition from city-prospered-suburb-prospered to city-declined-suburb-declined type in Northeast China was concentrated in Liaoning Province, and the proportion was approximately $43 \%$. The gradient transition was to city-balanced-suburb-balanced, which was mostly distributed in Jilin Province, accounting for about $60 \%$. The proportion of city administrative areas in Liaoning Province that changed from city-prospered to city-declined was $21 \%$; the proportion that changed from city-balanced to city-declined was $21 \%$; and the proportion that changed from suburb-prospered to suburb-declined was about $71 \%$. In Jilin Province, the proportion of city administrative areas that converted from city-prospered to city-declined was $25 \%$; the proportion that converted from city-balanced to city-declined was 13\%; and the proportion that converted from suburb-prospered to suburb-declined was about $13 \%$. In Heilongjiang Province, the proportion of city administrative areas that 
moved from city-prospered to city-declined was $33 \%$; the proportion that moved from citybalanced to city-declined was $17 \%$; and the proportion that moved from suburb-prospered to suburb-declined was about $17 \%$, and there were no changes from suburb-balanced to suburb-declined. In Eastern Inner Mongolia, the conversion proportion from city-prospered to city-declined was $67 \%$, and the proportion of suburb-prospered to suburb-declined was also $67 \%$. These results further suggested that the deterioration of the city administrative areas in Liaoning Province and Eastern Inner Mongolia was mainly affected by the rapid decline in the economic resilience level of the outer-suburbs and central-cities, while the deterioration of the city administrative areas in Heilongjiang and Jilin Province was mainly due to the rapid decline in the economic resilience level of central-cities.

\subsection{Differences of Central-Cities and Outer-Suburbs Economic Resilience}

Figure 1 shows the evolution of the industrial structures in China from 1978 to 2018. The proportion of the secondary industry in the country has fluctuated in the range of $50-40 \%$ in the past 40 years, and it dropped by $6.2 \%$ from $2007-2018$ - especially after 2012 when the proportion of tertiary industry increased significantly and exceeded that of the secondary industry. Relevant studies [42,43] have shown that since 2007-especially since 2012, when the economic growth rate has fallen from high-speed to medium-highspeed-regional economic development has clearly differentiated, and the fluctuation of the secondary industry has become the key point in China. The proportion of industrial-based secondary industries in GDP has declined, which has led to weak growth in the affected regions. At the same time, changes in the added value of secondary industries are also the main cause of regional industrial structure changes [44]. In addition, studies have shown that the industrial structure has been the most important factor affecting the resilience of the regional economy. Therefore, we explored the impact of industrial structure on the economic resilience of central-cities and outer-suburbs from the view of the industrial structure - that is, the proportion of the secondary industry.

By analyzing the correlation between the proportion of secondary industries and economic resilience in central-cities and outer-suburbs in Northeast China, we found that the two-stage correlation coefficients of the former were 0.33 and 0.57 , and the two-stage correlation coefficients of the latter were 0.38 and 0.77 . It was preliminarily shown that the impact of the proportion of the secondary industry on economic resilience increased with the upgrade of the risk of economic downturn, and the economic resilience of the outer-suburbs had a higher correlation with the proportion of the secondary industry. The changes in the proportion of the secondary industry in the central-cities and outer-suburbs in the two stages as shown in Figure 5 further confirmed the above judgment-that, overall, if the proportion of the secondary industry in the central-cities and outer-suburbs decreased more in the second stage, the worse the type after the mode conversion.

Table 3 shows that further analysis of the change in the proportion of secondary production in central-cities and outer-suburbs confirmed that in the pattern transition of city-prospered-suburb-prospered, the greater the decline in the proportion of the secondary industry, the greater the decline in the level of economic resilience in the central-cities and outer-suburbs. When the economic resilience level of the central-cities and outer-suburbs declined, the proportion of the secondary industry in the central-cities fell even more. Moreover, in the transition pattern of city-balanced-suburb-prospered, the change in the economic resilience level of the central-cities and the proportion of the secondary industry was not consistent, while the changes in the economic resilience level of the outer-suburbs kept the same degree of change in the proportion of the secondary industry. These results further verify that the economic resilience of outer-suburbs had a higher correlation with the proportion of the secondary industry. It also indicated that the economic resilience of outer-suburbs was more vulnerable and more heavily influenced by changes in the proportion of the secondary industry than the central-cities. 


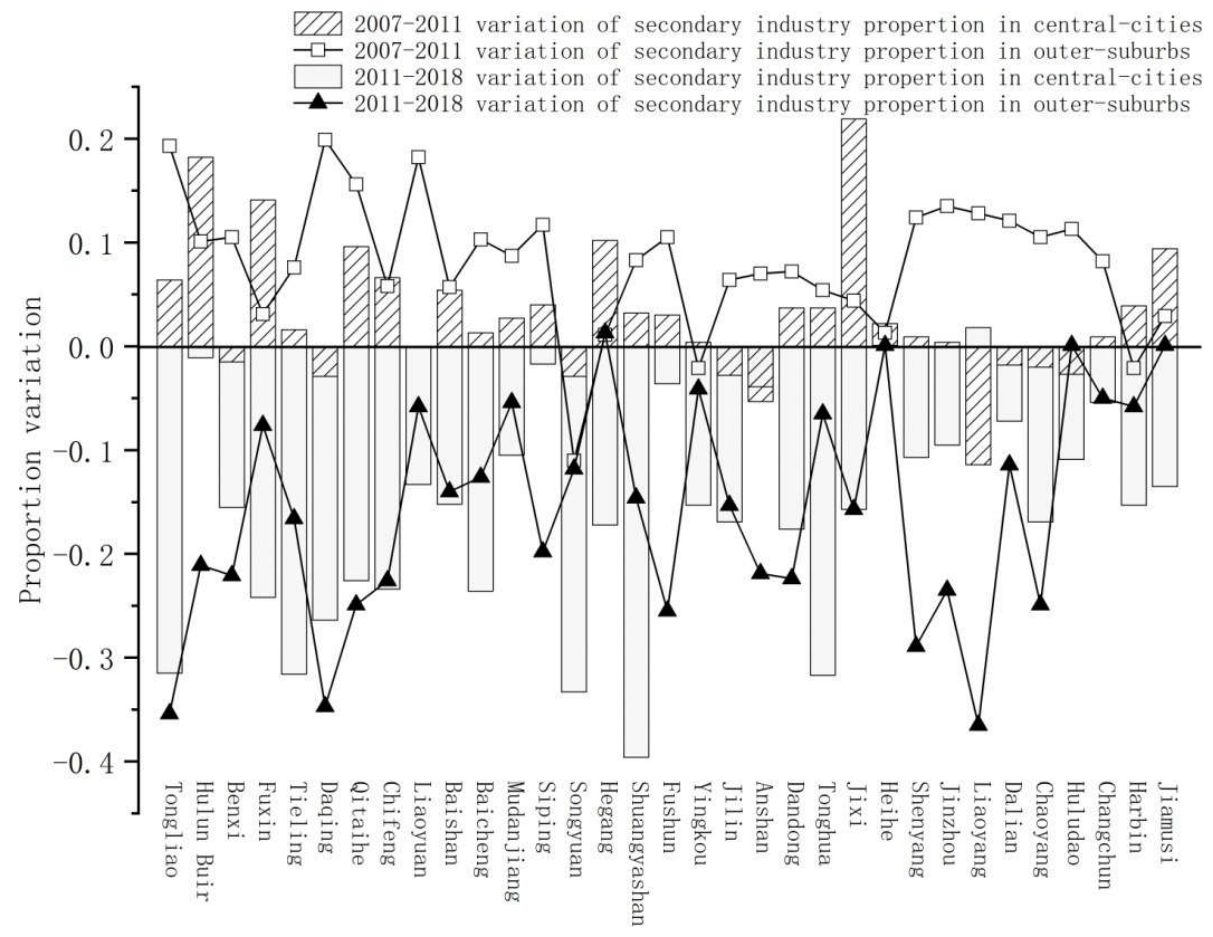

Figure 5. The changes in the proportion of secondary industry of the main central-cities and outersuburbs in Northeast China from 2007 to 2018.

Table 3. The changes in the proportion of secondary industry of major city administrative area types in Northeast China from 2011 to 2018.

\begin{tabular}{ccccc}
\hline Pattern Transition & $\begin{array}{c}\text { City-Declined-Suburb- } \\
\text { Declined (7) }\end{array}$ & $\begin{array}{c}\text { City-Balanced-Suburb- } \\
\text { Balanced (5) }\end{array}$ & $\begin{array}{c}\text { City-Declined-Suburb- } \\
\text { Balanced (4) }\end{array}$ & $\begin{array}{c}\text { City-Balanced-Suburb- } \\
\text { Declined (3) }\end{array}$ \\
\hline City-prospered-suburb- & $-0.218 /-0.232$ & $-0.172 /-0.121$ & $-0.230 /-0.112$ & $-0.119 /-0.150$ \\
prospered (19) & City-balanced (8) & City-declined (11) & Suburb-balanced (9) & Suburb-declined (10) \\
& -0.152 & -0.222 & -0.117 & -0.207 \\
\hline & City-declined-suburb- & City-declined-suburb- & City-balanced-suburb- & City-balanced-suburb- \\
battern transition & declined (2) & balanced (3) & $-0.061 /-0.296$ & $-0.115 /-0.078$ \\
& $-0.018 /-0.221$ & $-0.158 /-0.074$ & declined (3) & suburb-declined (5) \\
City-balanced-suburb- & City-balanced (9) & City-declined (5) & suburb-balanced (9) & -0.266 \\
prospered (15) & -0.097 & -0.102 & -0.077 & -0.27
\end{tabular}

Note: The number in brackets is the number of city administrative areas, central-cities or outer-suburbs, and the left and right slashes are the changes in the proportion of secondary production in the central-cities and outer-suburbs.

\section{Conclusions and Discussion}

\subsection{Conclusions}

Based on the analysis of the characteristics of regional economic resilience from the perspective of the center-peripheral relationship, we described the economic resilience of central-cities and outer-suburbs in Northeast China from 2007 to 2018. Further, we explored the differences in the impact of industrial structure on central-cities and outersuburbs. Our main conclusions are as follows: (1) Compared with 2007-2011, in the period of 2011-2018, the economic resilience level of the central-cities in Northeast China changed from a strong or moderate level to a moderate or weak level. And the economic resilience level of the outer-suburbs changed from strong to moderate or even weak. Moreover, the economic resilience level of the outer-suburbs changed more (for the worse) than that of central-cities. (2) The types of city administrative areas in Northeast China characterized by the combination pattern of the economic resilience level in the central-cities and the outer-suburbs, compared to 2007-2011 worsened from 2011-2018; the main types transformed from city-prospered-suburb-prospered and city-balanced-suburb-prospered 
to city-balanced-suburb-balanced and city-declined-suburb-declined. Among them, the deteriorations of Liaoning Province and Eastern Inner Mongolia's city administrative areas were greatly affected by the lower economic resilience level of both the outer-suburbs and central-cities, and the ones in Heilongjiang Province and Jilin Province were greatly affected by the lower economic resilience level of the central-cities. (3) It was further confirmed that the industrial structure had an important impact on the regional economic resilience. And it was initially found that the economic resilience of the outer-suburbs in Northeast China were more vulnerable and more heavily influenced by changes in the proportion of the secondary industry than the central-cities.

\subsection{Discussion}

Our conclusions are similar to those of existing studies that have found that the regions with a high proportion of the manufacturing industry were more negatively affected by their industrial structure during the 2008 financial crisis [25]. We found that the secondary industry had a different impact on the central-cities and outer-suburbs, which indicated that the change in the proportion of a secondary industry more easily affected the economic resilience of the suburban areas than that of central-cities in Northeast China. This conclusion can provide a useful reference for the development of city administrative areas, which are a combination of a central city and peripheral counties in China. Retaining a reasonable industrial structure plays an important role in maintaining stable growth in regional economy. In the new development stage of China, there must be an in-depth implementation of the resources needed to be a strong manufacturing country. An expanding domestic demand strategy, facing the needs of manufacturing upgrading, will lead to upgrades in household consumption. If city-prospered-suburb-prospered and city-balanced-suburb-prospered are ideal types to adapt to the development of city administrative areas in Northeast China, the secondary industry will still play a major role in the short-term rapid economic growth of suburbs and some central-cities in Northeast China. For instance, from 2011-2018, Beilin District of Suihua City and Panshan County of Panjin City were the only central-cities and outer-suburbs that still maintained a strong level of resilience, and they were the few central-cities and outer-suburbs with the largest increase in the proportion of the secondary industry. The secondary industry has been the main driving force for the development of the top 100 counties in China, and the top priority for future development is to expand the effective supply of the secondary industry. Therefore, for the development of suburbs, the unremitting development of industry can drive economic strength to grow rapidly and steadily. In the future, the adjustment of the industrial structure in the central cities and peripheral counties and cities will require a reasonable industrial division of labor and gradient levels as well as a trade-off between the diversification and specialization of the industrial structure and the regional economic growth rate.

Regional economic resilience is undergoing continuous improvement. Prior research has mostly examined countries or regions, provinces, and cities as basic units $[45,46]$. However, we used the perspective of the relationship of the central and peripheral to explore the relationship between the economic resilience of the central-cities and the outersuburbs in city administrative area, and we further expanded the research view of regional economic resilience. However, the analysis in our study still has limitations, and further research is needed. For example, a future study could focus on the diversity of industrial structure and could explore the impact of industrial structure on the economic resilience of the central-cities and outer-suburbs. This could help scientifically determine the choice of future city administrative area types to provide a basis for the path to improve economic resilience. In addition, more case studies-such as examining several cities within another country-could strengthen the comparative study of regional differences and further test the findings of our study. 
Author Contributions: Conceptualization, Q.L. and H.G.; methodology, Q.L.; formal analysis, Q.L. and Z.F.; resources, Q.L. and H.G.; writing-original draft preparation, Q.L. and W.L.; writingreview and editing, Q.L., H.G. and Z.F. All authors have read and agreed to the published version of the manuscript.

Funding: This work was supported by the National Natural Science Foundation of China $(42001117,42071219)$.

Institutional Review Board Statement: Not applicable.

Informed Consent Statement: Not applicable.

Data Availability Statement: All data generated or analyzed during this study are included in this published article.

Conflicts of Interest: The authors declare no conflict of interest.

\section{References}

1. Lu, D. Moderate-speed growth: Sustainable development of China's economy. Sci. Geogr. Sin. 2015, 35, $1207-1219$.

2. Liu, X.; Zhang, X.; Li, S. Measurement of China's macro economic resilience: A systemic risk perspective. Soc. Sci. China 2021, 42 , 12-32.

3. Zhu, S.; Yang, B.; Liu, Y. The dynamics of world economy geography and the role of China in economic globalization. Acta Geogr. Sin. 2022, 77, 315-330.

4. Fan, J.; Liu, H.; Wang, Y.; Zhao, Y.; Chen, D. “The Northeast China phenomenon” and prejudgment on economic revitalization in Northeast China: A primary research on stable factors to impact national spatial development and protection pattern. Sci. Geogr. Sin. 2016, 36, 1445-1456.

5. Guan, H.; Yang, Q.; Hao, F.; Feng, Z. Economic resilience characteristics of Shenyang city based on a perspective of industryenterprise-space. Acta Geogr. Sin. 2021, 76, 415-427.

6. Guan, H.; Zhang, P.; Liu, W.; Li, J. A comparative analysis of the economic transition process of China's old industrial cities based on evolutionary resilience theory. Acta Geogr. Sin. 2018, 73, 771-783.

7. Hu, X.; Zhang, W. Institutional evolution and regional economic resilience: A comparison of two resource exhausted cities in China. Geogr. Res. 2018, 37, 1308-1319.

8. Pendall, R.; Foster, K.A.; Cowell, M. Resilience and regions: Building understanding of the metaphor. Camb. J. Reg. Econ. Soc. 2010, 3, 71-84. [CrossRef]

9. Bristow, G.; Healy, A. Regional resilience: An agency perspective. Reg. Stud. 2014, 48, 923-935. [CrossRef]

10. Fröhlich, K.; Hassink, R. Regional resilience: A stretched concept? Eur. Plan. Stud. 2018, 26, 1763-1778. [CrossRef]

11. He, C.; Xia, X.; Li, M. Spatial difference and mechanisms of China's export trade regional resilience. Prog. Geogr. 2019, 38, 1558-1570. [CrossRef]

12. Tan, J.; Lo, K.; Qiu, F.; Zhang, X.; Zhao, H. Regional economic resilience of resource-based cities and influential factors during economic crises in China. Growth Change 2020, 51, 362-381. [CrossRef]

13. Peters, D.J. Community susceptibility and resiliency to COVID-19 across the rural-urban continuum in the United States. J. Rural Health 2020, 36, 446-456. [CrossRef] [PubMed]

14. Elias, G.; Adriana, B. Regional disparities in economic resilience in the European Union across the urban-rural divide. Reg. Stud. 2020, 54, 1200-1213.

15. Pavel, A.; Moldovan, B.A.; Kourtit, K.; Nijkamp, P. Urban or Rural: Does it make a difference for economic resilience? A modelling study on economic and cultural geography in Romania. Sustainability 2020, 12, 3776. [CrossRef]

16. Yuan, Y.; Gu, Y.; Xiao, Y. The spatial pattern and driving forces of poverty between central-cities and outer-suburbs in China. Hum. Geogr. 2017, 32, 40-47.

17. MacKinnon, D.; Cumbers, A.; Pike, A.; Birch, K.; McMaster, R. Evolution in economic geography: Institutions, political economy, and adaptation. Econ. Geogr. 2009, 85, 129-150. [CrossRef]

18. $\mathrm{Hu}, \mathrm{X}$. Review and prospect of regional economic resilience research. Foreign Econ. Manag. 2012, 34, 64-72.

19. Christopherson, S.; Michie, J.; Tyler, P. Regional resilience: Theoretical and empirical perspectives. Camb. J. Reg. Econ. Soc. 2010, 3, 3-10. [CrossRef]

20. Martin, R.L. Regional economic resilience, hysteresis and recessionary shocks. J. Econ. Geogr. 2012, 12, 1-32. [CrossRef]

21. Boschma, R. Towards an evolutionary perspective on regional resilience. Reg. Stud. 2014, 49, 733-751. [CrossRef]

22. $\mathrm{Hu}, \mathrm{X} . \mathrm{H}$. From coal-mining to coal-chemicals? Unpacking new path creation in an old industrial region in transitional China. Growth Change 2017, 48, 233-245. [CrossRef]

23. Martin, R.; Sunley, P. On the notion of regional economic resilience: Conceptualization and explanation. J. Econ. Geogr. 2014, 15, 1-42. [CrossRef]

24. Li, L.G.; Zhang, P.Y.; Tan, J.T. Review on the evolution of resilience concept and research progress on regional economic resilience. Hum. Geogr. 2019, 34, 1-7. 
25. Martin, R.; Sunley, P.; Gardiner, B.; Tyler, P. How regions react to recessions: Resilience and the role of economic structure. Reg. Stud. 2016, 50, 561-585. [CrossRef]

26. Luo, D.; Guo, Y.; Li, L.; Zhao, W. An analysis of regional difference and the reasons of financial crisis on China's economic impact Econ. Geogr. 2009, 29, 1448-1453.

27. Brakman, S.; Garretsen, H.; van Marrewijk, C. Regional resilience across Europe: On urbanisation and the initial impact of the Great Recession. Camb. J. Reg. Econ. Soc. 2015, 8, 225-240. [CrossRef]

28. Di Caro, P. Recessions, recoveries and regional resilience: Evidence on Italy. Camb. J. Reg. Econ. Soc. 2015, 8, 273-291. [CrossRef]

29. Dubé, J.; PolèSe, M. Resilience revisited: Assessing the impact of the 2007-09 recession on 83 Canadian regions with accompanying thoughts on an elusive concept. Reg. Stud. 2016, 50, 615-628. [CrossRef]

30. Xu, Y.; Wang, C. Influencing factors of regional economic resilience in the 2008 financial crisis: A case study of Zhejiang and Jiangsu Provinces. Prog. Geogr. 2017, 36, 986-994.

31. Liu, Y.; Ji, J.; Zhang, Y.; Yang, Y. Economic resilience and spatial divergence in the Guangdong-Hongkong-Macao Greater Bay Area in China. Geogr. Res. 2020, 39, 2029-2043.

32. Du, Z.; Jin, L.; Liu, Q. Industrial diversity, innovation, and economic resilience: Empirical analysis of the pearl river delta in the post-financial crisis era. Trop. Geogr. 2019, 39, 170-179.

33. Zhang, S.; Wang, C.; Li, B. Spatial difference of urban economic resilience and its influence factors in Northeast China. Hum. Geogr. 2019, 34, 73-80.

34. Li, L.; Zhang, P.; Guan, H.; Tan, J. Analysis of the regional economic resilience characteristics based on Shift-Share method in Liaoning old industrial base. Geogr. Res. 2019, 38, 1807-1819.

35. Guan, H.; Liu, W.; Zhang, P.; Lo, K.; Li, J.; Li, L. Analyzing industrial structure evolution of old industrial cities using evolutionary resilience theory: A case study in shenyang of China. Chin. Geogr. Sci. 2018, 28, 516-528. [CrossRef]

36. Tan, J.; Hu, X.; Hassink, R.; Ni, J. Industrial structure or agency: What affects regional economic resilience? Evidence from resource-based cities in China. Cities 2020, 106, 102906-102916. [CrossRef]

37. Sun, J.; Sun, X. Research progress of regional economic resilience and exploration of its application in China. Econ. Geogr. 2017, 37, $1-9$.

38. Van Oort, F.; De Geus, S.; Dogaru, T. Related variety and regional economic growth in across-section of European urban regions. Eur. Plan. Stud. 2015, 23, 1110-1127. [CrossRef]

39. Zhang, J.; Li, C. The evolution of urban-rural relationship in central cities of China during transformation period. Acta Geogr. Sin. 2012, 67, 1021-1030.

40. Guo, F.; Tong, L.; Qiu, F.; Xu, L. Spatio-temporal pattern and driving factors of urban-rural green development efficiency in Lunan Economic Belt. J. Nat. Resour. 2020, 35, 1972-1985.

41. Ma, H.; Wang, L. Research on effects of cycle stability and employment absorption of China's tertiary industry. China Soft Sci. 2009, 7, 144-150.

42. Wang, Q.; Liu, J.; Liu, D. Consistent fluctuation, regional coordinated development and idiosyncratic divergence of provincial business cycles in China. China Ind. Econ. 2019, 37, 61-79.

43. Fan, J.; Wang, Y.; Liang, B. The evolution process and regulation of China's regional development pattern. Acta Geogr. Sin. 2019, $74,2437-2454$

44. Tan, J.; Zhao, H.; Liu, W.; Zhang, P.; Chou, F. Regional economic resilience and influential mechanism during economic crises in China. Sci. Geogr. Sin. 2020, 40, 173-181.

45. Li, L.; Zhang, P.; Li, X. Regional economic resilience of the old industrial bases in China-A case study of Liaoning Province. Sustainability 2019, 11, 723. [CrossRef]

46. Tan, J.; Lo, K.; Qiu, F.; Liu, W.; Li, J.; Zhang, P. Regional economic resilience: Resistance and recoverability of resource-based cities during economic crises in Northeast China. Sustainability 2017, 9, 2136. [CrossRef] 